\title{
Neurophysiological mechanisms in abnormal reflex activities in cerebral palsy and spinal spasticity
}

\author{
G BAROLAT-ROMANA AND ROSS DAVIS
}

From the Institute of Neurosurgery, University of Torino, and from the Department of Neurosurgery, University of Michigan, Ann Arbor, and Mount Sinai Medical Center, Miami Beach

SUMMARY Dorsal root stimulation, carried out during operation in 80 spastic cerebral palsy patients and in one spastic quadriplegic patient, allowed a study of abnormal monosynaptic and polysynaptic reflexes. Frequency-related depression of the monosynaptic reflex was not present; increased activity through non-suppressed polysynaptic pathways was shown.

The exact pathophysiological mechanisms underlying spasticity which determine its clinical features have not been fully elucidated. Even a concise and universal definition of what entities the term spasticity includes is not presently available.

Much of the investigative efforts have been focused on the gamma loop and muscle spindles, on the assumption that the main pathophysiology was related to gamma hyperactivity. ${ }^{12}$ In recent years, however, evidence has accumulated that simple gamma hyperactivity cannot account for all the features of spasticity and even the classical view of the gamma loop organisation has undergone modifications. ${ }^{3-5}$

New evidence has shown that other mechanisms, such as lack of presynaptic inhibition and other abnormalities in interneuronal activity, may be involved in spasticity. ${ }^{6-10}$ These deductions resulted from the use of the tonic vibration reflex (TVR) and studies of the ratios of $H$ reflex (vibration) to $H$ reflex (control) and of Achilles tendon reflex to M response. ${ }^{79-12}$ Preliminary results of dorsal root stimulations (DRS) in cerebral palsy patients and its usefulness in the surgical management of spasticity have been reported previously by one of the authors. ${ }^{13-15}$ This paper deals with a detailed neurophysiological analysis of the abnormal reflexes in patients with spastic cerebral palsy and adds the findings in a neurophysiological study of a case of spinal spasticity.

Address for reprint requests: Dr Ross Davis, MD, Department of Neurosurgery, Mount Sinai Medical Center, 4300 Alton Road, Miami Beach, Florida 33140.

Accepted 24 October 1979

\section{Materials and methods}

\section{A CEREBRAL SPASTICITY}

Eighty subjects with cerebral palsy, ages between 5 and 25 , underwent functional posterior rhizotomy for the relief of spasticity. ${ }^{14}{ }^{15}$ Dorsal root stimulation (DRS) was used to show which roots or rootlets were involved in abnormally excitable circuits; we will refer to these as pathological roots or rootlets. All of the subjects presented with spasticity, that is, increased stretch reflexes, hyperactive tendon reflexes and abnormal postural patterns. In a few of them, dystonic or athetoid attitudes or both were associa ted with spasticity.

With the patient in the prone position, a D12-L1 laminectomy exposed the lumbar roots; the roots and rootlets were electrically stimulated in sequence. An average of about 105 rootlets were stimulated in each patient using bipolar hook electrodes which were separated by $1 \mathrm{~cm}$. Care in handling the roots was paramount, as even a minimal stretch or compression could modify their electrical excitability. The stimulation and recording equipment used was a Modular Electrophysiological System: Display and Recording Unit DFO6 MKII-N6, AVM6 Signal Averager and Biological Amplifier AA6 MK II-PA 467/15 (Medelec Limited, Woking, Surrey, England). Pulse duration was $0.5 \mathrm{msec}$. Ketamine hydrochloride was used for the anaesthesia. Reflex muscle responses were recorded using surface or needle electrodes. The EMG response following DRS is representative of synchronous multimotoneuronal activity.

Stimulation sequence for each root or rootlet was as follows. At $1 \mathrm{~Hz}$, the pulse amplitude was adjusted 
to obtain a reflex muscle contraction just above threshold. The muscle groups involved were then identified. With this pulse amplitude adjusted, the stimulation frequency was set at $50 \mathrm{~Hz}$. The reflex contraction patterns were observed, active muscle groups and patterns of contraction were identified. Occasionally, intermediate frequencies were used and adjustments to the DRS strength were made.

According to the various patterns observed, the criteria as to which roots or rootlets giving pathological responses should be sectioned were established. ${ }^{14}$ Thirty-six of the 80 cerebral palsy cases were analysed regarding the number and patterns of abnormal reflexes, and their clinical correlations.

\section{B SPINAL SPASTICITY}

Seven patients with chronic spinal cord injury underwent Bischof's myelotomy for the relief of intractable spasticity. ${ }^{1617}$ Essentially, the lower thoracic and lumbar cord was split laterally into anterior and posterior halves, resulting in a disruption of spinal reflexes. Technically, the extent of the myelotomy was determined by stimulating the dorsal roots and observing muscle contractions in the abdomen and lower extremities.

Prior to myelotomy, in one patient records were made from the T11 ventral root while the corresponding dorsal root was stimulated, providing a study of spinal pathophysiology in a very spastic subject. This patient was a 21 year old female who, four years previously, had a C5 fracture followed by immediate complete tetraplegia. The patient presented with severe spastic tetraplegia with marked flexor spasms of the lower limbs associated with hyperactive deep tendon reflexes, bilateral Babinski signs and an uninhibited neurogenic bladder. Touch, vibration and position sense were preserved while temperature and deep pain sensibility were absent below C6 level; pinprick sensation was partially present. The dorsal root was stimulated through silver wires, connected to a Grass stimulator (S8) with isolation unit. Monophasic pulses of $0.2 \mathrm{~ms}$ were used in the range of 1.0 to $5.0 \mathrm{~V}$ at $1 \mathrm{~Hz}$. Biphasic recordings from the ventral root were amplified through a Tektronic 3A9 differential amplifier and tape recorder for later analysis and photography (figs $6-8$ ). The recording procedure was shortened by the use of tape recording lasting about 30 minutes; anaesthesia was reduced to a lighter level using nitrous oxide and oxygen.

\section{Results}

In the 36 cerebral palsy cases analysed, 3840 rootlets were stimulated, either singly or in bundles, and determined to be either normal or pathological in

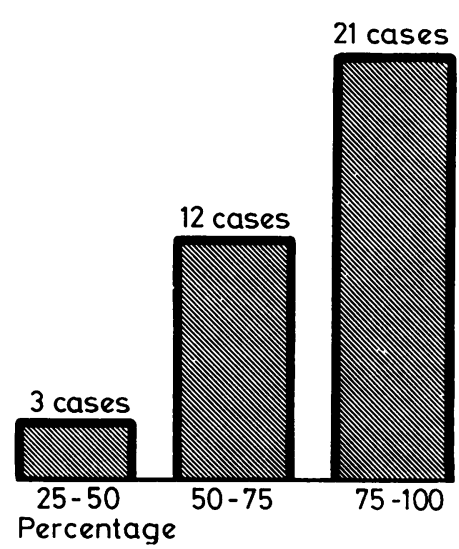

Fig 1 Distribution of rootlets involved in abnormal reflexes in 35 patients with cerebral palsy (CP).

their reflex responses (fig 1). Eighty per cent of the rootlets showed pathological responses, except in three cases only $25-30 \%$ of the rootlets produced such responses. Rootlets with the pathological responses had a lower threshold of stimulation to produce a detectable EMG response (fig 2). At or below a level of $1.0 \mathrm{~V}, 60 \%$ of the pathological rootlets were excited compared to $34 \%$ of the normal rootlets.

\section{Monosynaptic reflexes}

A CEREBRAL SPASTICITY

In the cerebral palsy patients, we studied the reflex muscle response to a just suprathreshold stimulus, applied to a dorsal root or rootlet. As the lowest threshold stimulus fires the largest fibres (Ia afferents), the EMG response results from a synchronous monosynaptic multineuronal discharge. ${ }^{18}$ Three

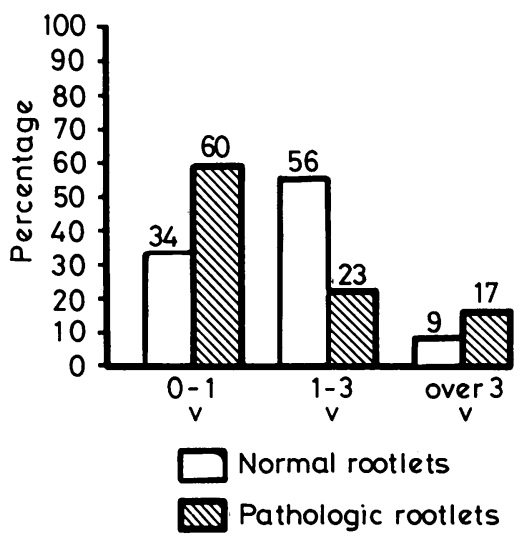

Fig 2 Percentage distribution of normal and abnormal rootlets according to stimulation threshold. 
main features of the monosynaptic reflex arc have been observed:

1 Normal reflex activity: with $1 \mathrm{~Hz}$ DRS the reflex response is normally repeatable and without loss of amplitude (fig $3 \mathrm{~A}$ ). When the stimulation frequency is increased, the multineuronal reflex response is reduced in amplitude (fig $3 \mathrm{~A}, 10$ and $20 \mathrm{~Hz}$ ). At frequencies between 20 and $50 \mathrm{~Hz}$, there is an early failure to follow and the amplitude of the response is more reduced (fig $3 \mathrm{~A}$ ). At $50 \mathrm{~Hz}$ only the first stimulus succeeds in producing a reflex muscle contraction. Fasano, et al, ${ }^{15}$ recording from the ventral roots showed a similar failure of transmission at $50 \mathrm{~Hz}$, so demonstrating the failure at the spinal level rather than at the myoneural junction or muscle fibre. A similar decrease in amplitude of the monosynaptic response with increasing stimulation frequency and absence of the subsequent responses after the first response was observed by Decandia et al. ${ }^{19}$ They stimulated Ia afferents in anaesthetised cats and recorded from single filaments of the ventral roots.

In the patients with cerebral palsy, normal monosynaptic activity was found in approximately $20 \%$ of the roots or rootlets stimulated, with considerable variation from case to case.

2 Abnormal reflex activity. a Increased activity of the reflex arc. At $50 \mathrm{~Hz}, 80 \%$ of the stimulated roots or rootlets showed pathological reflex activity

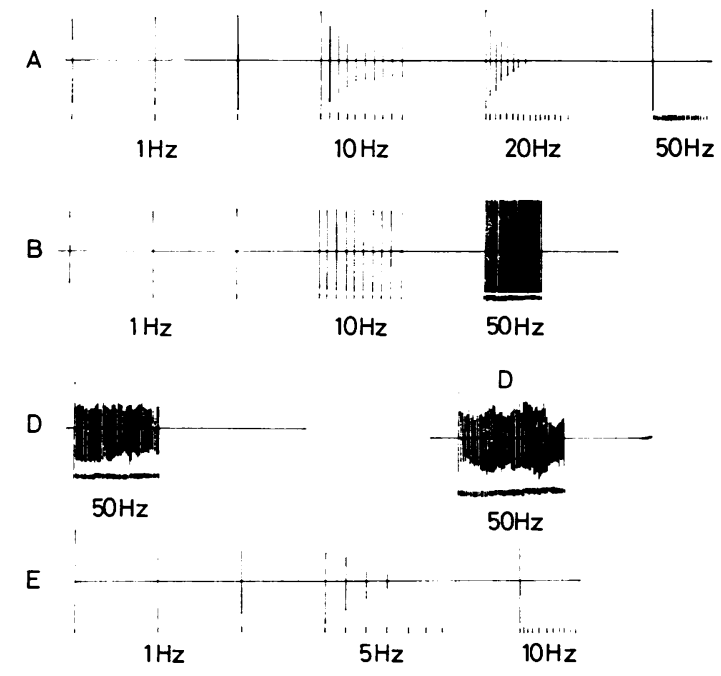

Fig 3 Main types of monosynaptic reflex EMG responses evoked in the $C P$ patients following repetitive $D R S$. $A$ : normal reflex activity. $B-D$ : abnormally increased reflex activity. E: abnormally decreased reflex activity. following stimulation, about $70 \%$ were involved in abnormal monosynaptic reflex activity as shown in figs 3-5. Some $50 \%$ of the abnormal reflexes were attributable to abnormal polysynaptic activity (see below). Further analysis of our earlier data ${ }^{13-15}$ confirmed that these segmental monosynaptic pathways transmit without failure and show three basic patterns. The first pattern is the ability of the system to transmit without any sign of failure, as seen in fig 3B. The second pattern shows ability to follow the high frequency $(50 \mathrm{~Hz})$ but with reduced amplitude (fig 3C). The third pattern shows a cyclic variability of the amplitude (fig 3D).

A further demonstration of this abnormality is seen when recording from two different muscle groups (fig 4, tibialis anterior A; triceps surae $\mathrm{B}$ ) following stimulation of one dorsal root at $50 \mathrm{~Hz}$. With a progressive increase of stimulus intensity from zero, the tibialis anterior shows no reflex activity while the triceps surae shows a reflex contraction proportional in amplitude to the increase in stimulus intensity. When the stimulus intensity is threshold and applied at $50 \mathrm{~Hz}$ the tibialis muscle, however, responds with a normal pattern in that only the first transmission occurs. But the triceps muscle contracts and abnormally follows the $50 \mathrm{~Hz}$ stimulation throughout with less amplitude (fig 4B).

An abnormal and in our experience unique, response was observed following repetitive stimulation at various frequencies (fig 5). Although the trains of stimuli were continuous, the reflex activity occurred only in periodic bursts of $600-800 \mathrm{~ms}$. The intervals between each burst were between 800 and $1000 \mathrm{~ms}$, regardless of the frequency of stimulation $(5-50 \mathrm{~Hz})$.

b Decreased activity of the reflex arc. At stimulation frequencies below $5 \mathrm{~Hz}$, Fasano et al ${ }^{15}$ described depression and failure of discharge. In further analysis of this data, circuits displaying such a feature (fig 3E) appeared to occur rarely.

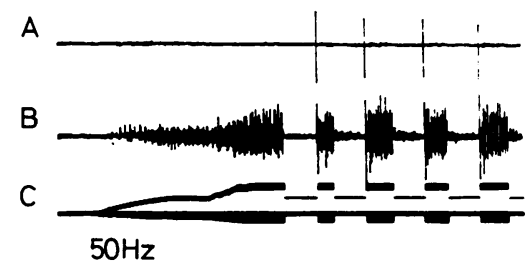

Fig $4 C P$ patient. Stimulation of a dorsal root at $50 \mathrm{~Hz}$ EMG recording on tibialis anterior $(A)$ and triceps surae $(B)$. C: stimuli. Left side of recording: $50 \mathrm{~Hz}$ stimulation with progressive increase in strength. Right side of recording: $50 \mathrm{~Hz}$ constant stimulation (liminal for monosynaptic reflex). 


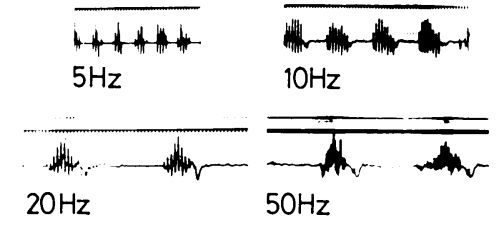

Fig 5 CP patient. Stimulation of a dorsal root at different frequencies. Upper traces: stimuli. Lower traces: $E M G$ reflex responses.

\section{B SPINAL SPASTICITY}

In the 21 year old patient with spastic tetraplegia undergoing myelotomy, the following spinal cord physiology study was undertaken. With both stimulating and recording electrodes approximately $70 \mathrm{~mm}$ from the spinal cord on the dorsal and ventral root (fig $8 \mathrm{H}$ ), single shocks to the dorsal root (DR) evoked a triphasic ventral root (VR) potential at a constant latency of $2.0 \mathrm{~ms}$ (fig $6 \mathrm{~A}$ ) giving rise to a conduction velocity of about $70 \mathrm{~m} / \mathrm{s}$ for the entire reflex.

The earliest component of the VR discharge appears with stimulus intensities of approximately $1.0 \mathrm{~V}$ and progressively increases in amplitude with stimulus intensity (fig $6 \mathrm{C}$-E). This initial synchronous low threshold response is presumably due to activation of the monosynaptic spinal reflex. ${ }^{2021}$ It is followed by relatively prolonged activity which appears only at higher stimulus intensities (fig 6 B, D, E) at a latency of $4 \mathrm{~ms}$. At the intensities required to evoke this later activity, contraction of the abdominal muscles at the umbilical level followed each stimulus. It is possible, therefore, that this later
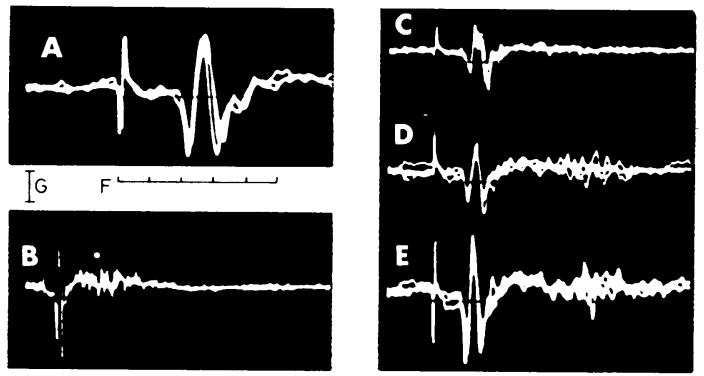

Fig 6 Ventral root responses to dorsal root stimulation in the subject with spinal spasticity. TI1 segment, dorsal and ventral roots intact. Stimulus of $0.2 \mathrm{~ms}$ duration at $1 \mathrm{~Hz}$. All traces show three superimposed sweeps. A-B: initial, triphasic monosynaptic reflex $(A)$ followed by more prolonged polynaptic reflex (below dot in B). $4 \cdot 0 \mathrm{~V}$ stimulation. $C$-E: increasing stimulus intensity from $C, 1 \cdot 5 \mathrm{~V}$; $D, 2 \cdot 0 \mathrm{~V} ; \mathrm{E}, 4 \cdot 0 \mathrm{~V}$. Calibration marks in $F$ are $1 \mathrm{~ms}$ for $A, 5 \mathrm{~ms}$ for $B$ and $2 \mathrm{~ms}$ for $C-E$. $G$ : 100 microvolts.
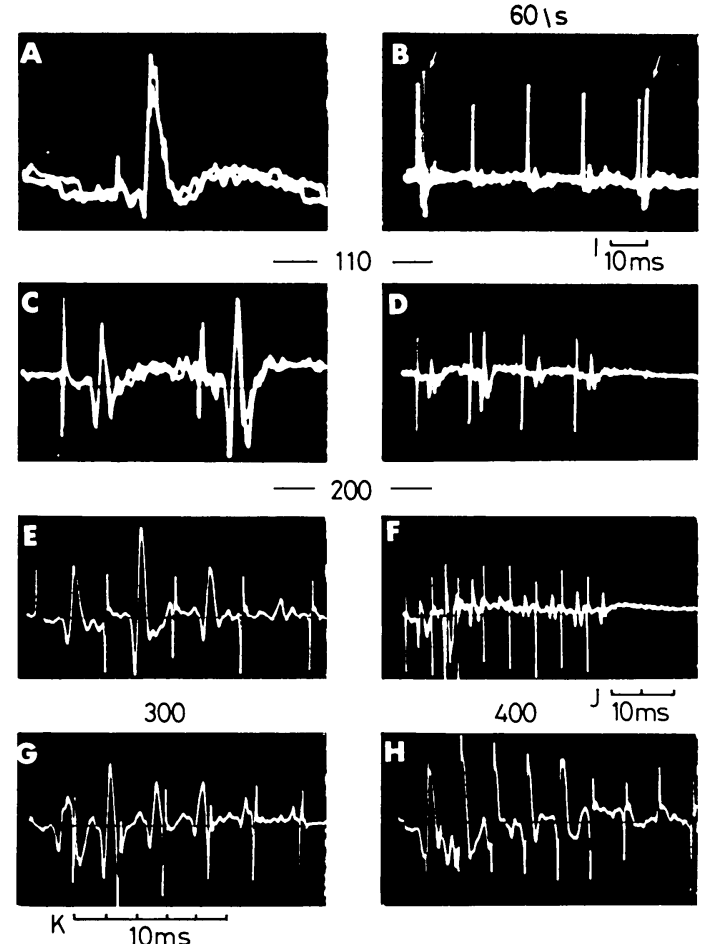

Fig 7 Ventral root responses to repetitive dorsal root stimulation. Same conditions as in fig 6.

$5 \mathrm{~V}$ stimulation throughout, but gain varies among frames. A: 3 sweeps of 250 microV control response. $B-H$ : single sweeps at different stimulation

frequencies (as indicated above each trace).

activity could be due to the resulting spindle afferent activity, since the reflex loop was intact. However, the estimated conduction distance to the site of visible muscle contraction was $40-50 \mathrm{~cm}$; and impulses in Ia fibres, travelling at a rate of $100 \mathrm{~m} / \mathrm{s}$, would require 8 to $10 \mathrm{~ms}$ to complete the loop. Furthermore, these delayed discharges appeared while the monosynaptic response was depressed (fig $8 \mathrm{~A}$ ). The delayed responses were therefore attributed to polysynaptic reflex activity evoked by dorsal root stimulation. ${ }^{21} 22$

Two methods were used to assess the excitability of these reflexes. Trains of repetitive stimuli at $5 \mathrm{~V}$ were delivered at various frequencies while monitoring the monosynaptic reflex responses (fig 7). At frequencies of $60 \mathrm{~Hz}$ the first and fifth stimuli evoked responses of nearly controlled amplitude, but there is a marked depression of reflex excitability during the intervening $67 \mathrm{~ms}$ (fig 7B). At higher stimulation frequencies $(100-400 \mathrm{~Hz})$, monosynaptic reflex excitability is increased for approximately $10 \mathrm{~ms}$ following the initial stimulus (fig $7 \mathrm{C}-\mathrm{H}$ ); 


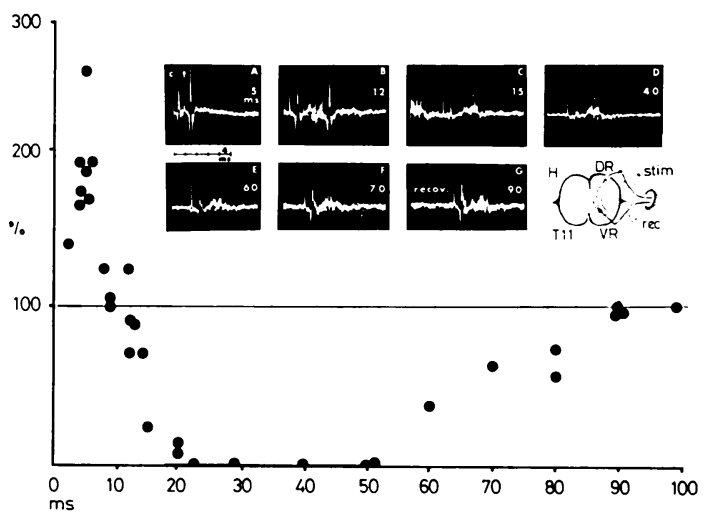

Fig 8 Excitability cycle of monosynaptic ventral root reflex. Subject with spinal spasticity.

Experimental conditions as shown in $H$. Graph shows the peak-to-peak amplitude of the monosynaptic reflex plotted as percentage of control amplitude (ordinate), each point being a single determination. Abscissa gives the interval between the conditioning ( $c$ in $A$ ) and testing ( $t$ in $A$ ) stimuli, each being $4 \mathrm{~V}$ and delivered at $1 \mathrm{~Hz}$ from a single dorsal root electrode. $A-G$ are sample records taken at the $c-t$ intervals indicated at the right of each trace of 3 superimposed sweeps.

subsequent stimuli produced transmissions but at a decreased amplitude (fig 7F).

This response pattern was confirmed by a detailed examination of the excitability cycle as shown in fig 8 . In this test, pairs of identical DR stimuli were delivered at various intervals at a rate of $1 \mathrm{~Hz}$, each stimulus being of sufficient strength to evoke a polysynaptic DR response. It was observed that the period of increased monosynaptic reflex excitability was 10-12 ms, and it overlapped the onset and duration of the polysynaptic responses. During this period, the amplitude of the second or testing response was increased by $2-3$ times the control amplitude (fig 8A, B). This confirmed the presence of a hyperexcitable state in the DR-VR synapse system following a transmission. Of considerable interest was the absence of the polysynaptic response during the facilitated monosynaptic response (fig $8 \mathrm{~A}, \mathrm{~B})$ and its subsequent reappearance from $12 \mathrm{~ms}$ onwards. The monosynaptic response failed to appear from approximately $20 \mathrm{~ms}$ to $60 \mathrm{~ms}$ after the initial transmission, recovering at $90 \mathrm{~ms}$. Throughout this period of depressed monosynaptic activity, the polysynaptic activity was present and appeared normal (fig $8 \mathrm{C}-\mathrm{G}$ ).

\section{Polysynaptic reflexes}

\section{A CEREBRAL SPASTICITY}

Polysynaptic activity is minimal or absent when large myelinated afferents are stimulated at a threshold liminal for the monosynaptic reflex in the anaesthetised cat and in man. ${ }^{21-23}$ Following repetitive stimulation, similar minimal polysynaptic activity is seen in the cat ${ }^{24}$ and in the EMG recordings of Cook $^{25}$ and of Barolat-Romana ${ }^{26}$ in normal humans.

In the cerebral palsy series, however, $50 \%$ of the dorsal roots or rootlets stimulated repetitively at a threshold for the monosynaptic reflex showed marked polysynaptic activity. Although not evident at $1 \mathrm{~Hz}$ stimulation, this polysynaptic activity was progressively built up as the frequency increased.

At $50 \mathrm{~Hz}$ stimulation the polysynaptic activity was characterised by: 1 a delayed latency of about 150-200 ms with a progressive increase in amplitude. With cessation of the stimulation, the activity continued for a few hundred ms with a decreasing amplitude (fig 9A); 2 an interferential EMG recording (fig 9A); 3 an irradiation phenomena involving multimuscular groups and multisegmental levels. Such irradiation patterns vary from patient to patient and from root to root; other muscle groups in the ipsilateral or contralateral lower extremities can be involved as well as the upper extremities and the muscles of the neck and trunk.

Two definite patterns of abnormal irradiation have been commonly observed: bilateral hip adductors contraction: with $1 \mathrm{~Hz}$ stimulation the ipsilateral hip adductors contract whereas at $50 \mathrm{~Hz}$ bilateral contraction of hip adductors occur; and triple flexion response: at $1 \mathrm{~Hz}$ stimulation a muscle group contracts in the lower extremities whereas at $50 \mathrm{~Hz}$ stimulation, contraction of hip flexors, hamstrings and tibialis anterior occur forming the triple flexion response. In fig 10 the quadriceps muscle responded monosynaptically at $1 \mathrm{~Hz}$ but when the stimulation frequency was raised to $50 \mathrm{~Hz}$ polysynaptic activity occurred in the tibialis anterior, hamstrings and biceps brachii; simultaneously a triple flexion

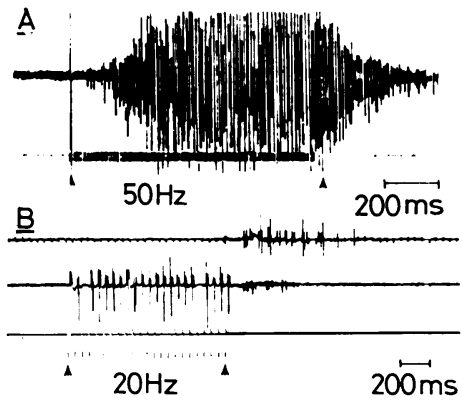

Fig $9 C P$ patients. A: Dorsal root stimulation at $50 \mathrm{~Hz}$ EMG recording. B: Dorsal root stimulation at $20 \mathrm{~Hz}$ EMG recording on tibialis anterior (upper) and hamstrings (lower). 


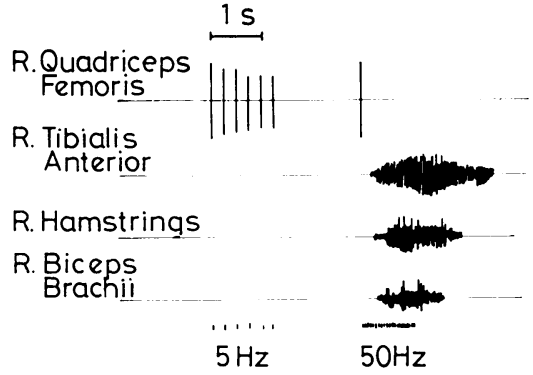

Fig $10 C P$ patient. Stimulation of one dorsal root at 5 and $50 \mathrm{~Hz}$ EMG recording in four muscle groups.

response was observed in the lower limb as well as flexion of the elbow.

An unusual observation is shown in fig 9B, where a root was stimulated at $20 \mathrm{~Hz}$ and shows polysynaptic activity starting after the burst stimuli have finished in both the hamstrings and tibialis anterior. It should be pointed out that only the hamstrings muscle responds during stimulation showing a monosynaptic response.

\section{B SPINAL SPASTICITY}

Ventral root polysynaptic activity was clearly identified following an increase in the strength of stimulation of the DR at $1 \mathrm{~Hz}$ (fig 6B-E). Its latency is approximately $4 \mathrm{~ms}$ onwards, lasting $14 \mathrm{~ms}$. The time of maximum activity is about $10 \mathrm{~ms}$.

Although bipolar recording does not permit a detailed analysis of the dispersed polysynaptic discharges, it is obvious from the responsiveness cycle (fig 8 ) that it is absent while the monosynaptic activity is initially enhanced. The polysynaptic responses return at $12-15 \mathrm{~ms}$ and are not depressed during the period of profound monosynaptic reflex depression (fig 8).

\section{Clinical correlations}

Correlations between the observations made during operation and the clinical features have been made in the 36 cases selected for this study. Fig 11 shows the relationship between the clinical features (topographical extent of spasticity, severity of increase of stretch reflexes and of startle reactions) and the proportion of rootlets evoking pathologic reflex activity.

Twenty-six cases clinically showed spasticity affecting the lower limbs only. The number of rootlets with abnormal reflex activity was above $75 \%$ of all the stimulated rootlets in 15 cases $(57 \%)$. A similar percentage of pathologic rootlets was found in 10 subjects with spasticity affecting all four extremities.

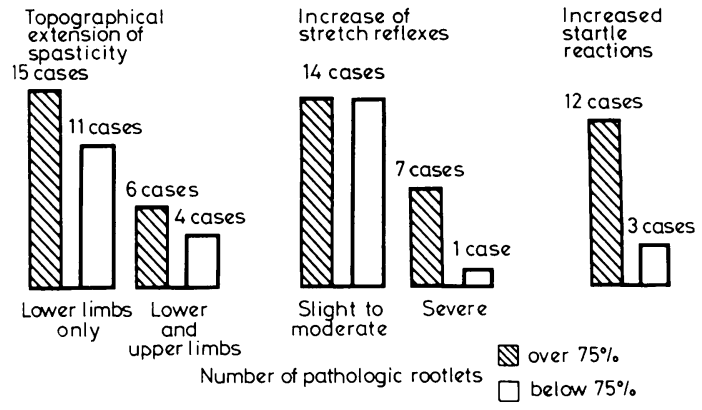

Fig 11 Correlations between percentage of pathologic rootlets and three clinical features in 35 CP patients.

Twenty-eight cases showed a slight to moderate increase of their stretch reflexes. The number of pathologic rootlets was above $75 \%$ in 14 cases $(50 \%)$. However, out of eight subjects with greatly increased stretch reflexes, seven had more than $75 \%$ of their rootlets evoking pathological reflex activity.

Fifteen subjects showed abnormally increased startle reactions. The number of pathologic rootlets was more than $75 \%$ in 12 of these patients $(80 \%)$ (fig 11).

On stimulation of the lumbar roots, nine cases showed a polysynaptic irradiation to the upper limbs. Eight of them showed signs of spastic involvement of the upper limbs in the preoperative clinical picture.

Of five subjects with bilateral contract:on of hip adductors to stimulate at $1 \mathrm{~Hz}$ stimulation (a most unusual finding in the overall series), four had severe spasticity involving these muscle groups.

The correlation between the clinical picture and the recordings of reflex activity at operation in three cases is shown in fig 12. The muscles responding to DRS at 1 and at $50 \mathrm{~Hz}$ were noted.

Case 1 presented with spastic paraparesis mainly affecting the quadriceps, the hip adductors and the triceps surae. At operation, with stimulation at $1 \mathrm{~Hz}$ the quadriceps and hip adductors were reflexly activated from stimulation of most of the roots. With $50 \mathrm{~Hz}$ stimulation a marked pathologic involvement of quadriceps, hip adductors and triceps surae, with bilateral irradiation of contraction occurred (fig 12).

Case 2 was a severe spastic tetraparetic patient with dystonic features. The spasticity mostly involved hip flexors, hamstrings and triceps surae. All the muscle groups of the lower extremities responded according to the laws of segmentary innervation with $1 \mathrm{~Hz}$ stimulation. At $50 \mathrm{~Hz}$ stimulation, however, the predominant pattern of reflex muscle response was one of triple flexion retraction (tibialis anterior, 

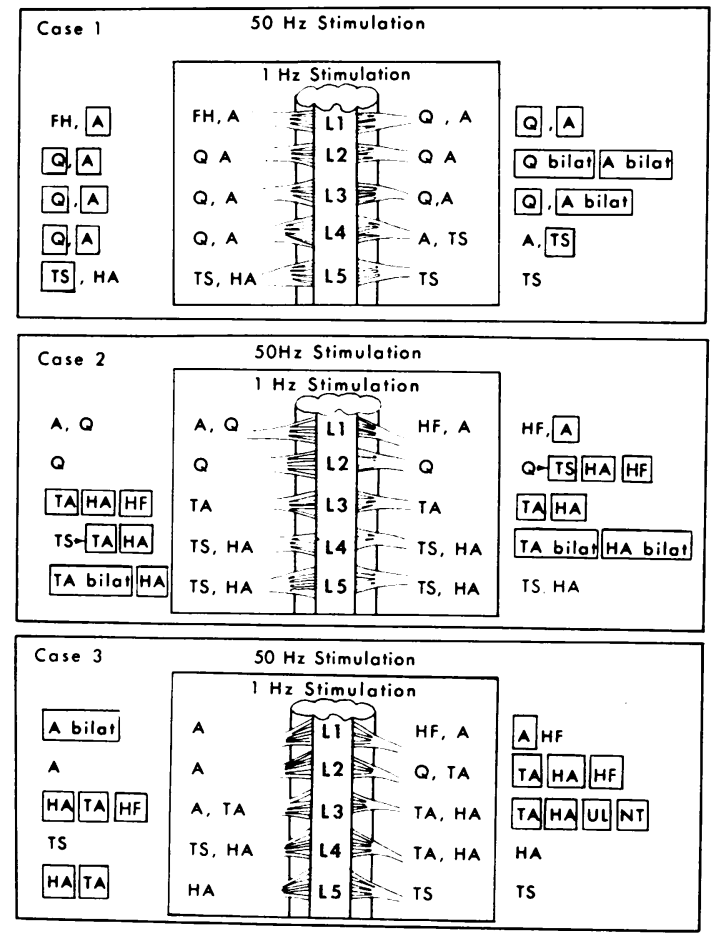

Fig 12 Intraoperative findings of the distributions of reflex activity following $1 \mathrm{~Hz}$ and $50 \mathrm{~Hz} \mathrm{DRS}$ in 3 cases of CP. HF: hip flexors; A: hip adductors; $Q:$ quadriceps; TA: tibialis anterior; TS: triceps surae; HA: hamstrings; $U L$ : upper limb; $N T$ : neck and trunk. Enclosure of muscle groups indicates abnormal reflex responses.

hamstrings) of the lower limbs; bilateral irradiation of the response occurred with right L4 and left L5 stimulation (fig 12).

Case 3 clinically showed a severe spastic tetraparesis mostly affecting hip adductors and hamstrings, with some athetoid features. With $50 \mathrm{~Hz}$ stimulation, the pathologic circuits mostly involved the hip adductors, the hamstrings and tibialis anterior; irradiation of the upper limbs, trunk and neck muscles occurred (fig 12).

\section{Discussion}

\section{A NEUROPHYSIOLOGICAL MECHANISMS}

1 Monosynaptic reflexes: In the anaesthetised cat, early observations by Jefferson et al, ${ }^{27}$ by Lloyd $e t$ $a l^{28}$ and, more recently, by Decandia et al, ${ }^{19}$ showed that a depression occurs when a monosynaptic reflex pathway is subjected to repetitive stimulation. Similar observations have been made in normal humans. ${ }^{26} 29$
Lloyd et $a l^{28}$ attributed low frequency (below $10 \mathrm{~Hz}$ ) depression to presynaptic mechanisms and high frequency, (above $10 \mathrm{~Hz}$ ) depression to motoneurone subnormality, that is to postsynaptic mechanisms. Decandia et al, ${ }^{19}$ later proved that failure of transmission with frequencies up to $50 \mathrm{~Hz}$ following repetitive activation of Ia afferents is due to presynaptic mechanisms. Two mechanisms are involved in presynaptic depression of the monosynaptic reflex. One is depletion of the available transmitter in the presynaptic terminals, ${ }^{30}$ and the other is presynaptic inhibition. ${ }^{4}$ The time course of presynaptic inhibition is such that it begins with a latency of about $5 \mathrm{~ms}$, reaches its maximum at about $20 \mathrm{~ms}$ and lasts longer than $200 \mathrm{~ms}^{4}$

No reflex effects secondary to muscle spindle contraction seem to be involved, as similar frequency dependent depression has been observed in experiments where both the afferent nerve and the corresponding ventral roots have been sectioned. ${ }^{31}{ }^{32}$

The time course of monosynaptic reflex depression we have observed in the roots or rootlets with normal reflex activity (fig 3A) closely corresponds to the one of presynaptic inhibition on Ia afferents. Minimal or no depression, in fact, is observed when the interval between the stimuli is one second; depression becomes evident when the interval is $200 \mathrm{~ms}(5 \mathrm{~Hz}$ stimulation) and is maximal when the interval is $20 \mathrm{~ms}$ ( $50 \mathrm{~Hz}$ stimulation).

In cats and rats made rigid by experimental spinal cord asphyxia, monosynaptic reflexes exhibit less or no depression during low and high frequency repetitive stimulation. ${ }^{24}$ 31-33 Our data (fig 3B-D) closely resembles their findings, and shows a lack of frequency-related inhibition of the monosynaptic reflex. As Delwaide ${ }^{7}$ stated, in cerebral spasticity all the propioceptive afferent impulses are able to gain direct access to the motoneuronal pool and exert a motor influence. It has been postulated by Delwaide ${ }^{7}$ and Ashby et al $^{9}$ that presynaptic inhibition is lacking in established spasticity. Our data suggests that there may be a lack of presynaptic mechanisms on the regulation of Ia afferents in cerebral spasticity, although other mechanisms, such as direct motoneuronal hyperexcitability and reduced postsynaptic inhibition, cannot be excluded.

An important observation from our study is that normal (fig $3 \mathrm{~A}$ ) or even reduced (fig $3 \mathrm{E}$ ) reflex activity of the monosynaptic arc can be observed in the spinal circuits of subjects with spasticity.

A remarkable feature of the results of DRS in the subject with spinal spasticity is the ability of the monosynaptic arc to follow stimuli to frequencies as high as $400 \mathrm{~Hz}$ (fig 7). This correlates with the marked increase (up to $200-300 \%$ of the conditioning response) of the test reflex response during the early 
facilitatory phase (fig 8). Early facilitation can normally reach $120-160 \%$ of the conditioning shock $^{34}$ and is normally present only after a submaximal afferent volley. ${ }^{35}$ Such an increase of this reflex activity with supramaximal stimuli is likely to reflect hyperexcitability of the synaptic system or reduced postsynaptic inhibition or both. The remaining part of the excitability cycle following paired supramaximal stimuli (fig 8 ) shows that early recovery starts at $60 \mathrm{~ms}$ and reaches $100 \%$ by $90 \mathrm{~ms}$. Studies in normal subjects ${ }^{35}$ show that, with strong volleys, recovery from early depression does not begin before $150 \mathrm{~ms}$ and does not reach $50 \%$ of the conditioning volley. Studies in subjects with spinal spasticity have similarly shown earlier recovery and increased facilitation following early depression. ${ }^{35}$

Mechanisms involved in early depression and subsequent facilitation of the $\mathrm{H}$ reflex excitability cycle are complex and still controversial. Presynaptic mechanisms seem to play an important role in depression, ${ }^{36}$ while subsequent facilitation has been attributed to long-loop facilatatory reflexes ${ }^{36}$ or to an increase of the central excitatory state of alpha motoneurones. ${ }^{37}$ Alterations in the first hundred ms of the excitability cycle (fig 8) can therefore be attributed to defective presynaptic mechanisms or excessive activity of the later facilitatory mechanisms or both.

2 Polysynaptic reflexes: DRS in patients with cerebral spasticity has shown an abnormal activation of widespread polysynaptic pathways following repetitive volleys on large myelinated afferents. It is interesting to note that polysynaptic activity is usually absent with low frequency stimulation, and builds up only when the frequency is increased. This means that mechanisms normally preventing diffusion through polysynaptic pathways are reduced and that they are particularly susceptible to temporal summation.

It is to be noted that polysynaptic irradiation can occur in synaptic circuits which do not respond monosynaptically (fig 10). As there is a correlation between the topographical extension of spasticity and the amount of polysynaptic irradiation seen on stimulation of dorsal roots, such a widespread reflex activation of polysynaptic pathways can be responsible for global synkinesias and lack of selective voluntary movement. Similar observations have been made by Dimitrijević et $a \mathbf{l}^{38}$ in spinal spasticity. They, in fact, observed that after a tendon tap, the antagonist may show a prolonged polysynaptic activity even though no activity was induced in the agonist except for its first synchronous discharge of motor units.

It must be pointed out that no uniformity exists in the spinal circuits of spastic subjects at different segmental levels. Different roots or subgroups of rootlets, even in the same subject, can be involved in normal or abnormal reflex activity.

Lack of frequency-related depression of the monosynaptic reflex and abnormal spreading through polysynaptic pathways are two independent variables. This means that either abnormality or both can be present, although to a different extent in the same subject. The great variability of the spinal circuits found in the patients with cerebral palsy derives from the various intermingling of these abnormal reflex activities.

The polysynaptic response observed in the excitability cycle of the subject with spinal spasticity (fig 8) is largely of cutaneous origin and should be normally be depressed for over $\mathbf{3 0 0} \mathrm{ms}$ after a single conditioning cutaneous volley primarily because of presynaptic inhibition. ${ }^{39}$ Our investigations do not permit a quantitive analysis of this discharge, but records show no signs of the pronounced depression which might be expected. As shown by Van Harreveld et $a l,{ }^{33}$ Murayama et al, ${ }^{24}$ and Gelfan, ${ }^{31}$ asphyxiation of the spinal cord for several minutes leads to profound loss of interneurones and considerable attenuation of polysynaptic activity. The presence of a polysynaptic reflex as shown here indicates the presence of sufficient functional interneurones to mediate a ventral root response, but the absence of an obvious postdischarge depression might reflect the functional loss of interneurones mediating presynaptic inhibition.

This hypothesis must, of course, stand the test of more extensive observation and experimentation than recorded here, but is especially attractive in view of the well known clinical observation that the flexor spasms seen in these patients are frequently triggered by cutaneous stimuli, the spinal input most effectively influenced by presynaptic inhibition. ${ }^{39}$

\section{B CLINICAL CORRELATIONS}

The data shown in the paragraph on clinical correlations shows the relationship that exists between the characteristics of the spinal circuits and the clinical features in subjects with cerebral spasticity. The main correlations can be summarised as follows: 1 The distribution of abnormal reflexes produced by lumbar root stimulation correlate closely, in the majority of cases, with the distribution of spasticity seen in the lower extremities.

2 The proportion of lumbar rootlets with abnormal responses is related to the severity of increase of stretch reflexes and not to the topographical extent of spasticity (fig 11). This means that patients with markedly hyperactive stretch reflexes, even if confined to the lower limbs only, have a larger number of pathologic rootlets than subjects with mildly in- 
creased stretch reflexes involving all four extremities. 3 Similarly, there is a direct correlation between the number of rootlets with abnormal responses and the severity of increase of startle reactions (fig 11). 4 There is a correlation between the irradiation of the reflex response to the upper limbs, as elicited at surgery, and the spasticity topography as judged clinically preoperatively. As presented above, eight out of nine cases with polysynaptic irradiation to the upper limbs had a spastic involvement of the upper extremities in the preoperative evaluation.

A main conclusion is that in the reflex motor organisation of each subject with cerebral palsy, the overall pattern of abnormal motor responses can be revealed by activation of spinal circuits at different segmental levels. In the normal subject there are alternatives in the pattern of response to stimuli. The spastic patient particularly with cerebral palsy has, however, limited alternatives because of a stereotype response pattern which controls the segmental reflex activities. In case 1 (fig 12), for instance, which clinically showed extensor hypertonia of the lower extremities, the quadriceps was constantly activated throughout DRS, independently of the segmental level of stimulation.

These observations are similar to what Dimitrijevic et $a l^{38}$ observed in spinal spasticity. They concluded that two principles govern the involvement of reflex polysynaptic pathways in this condition. They found, in fact, that once certain motoneurones are active, any stimulation will facilitate these motoneurones; at the same time, pathways to certain motoneurones are more easily available, and all stimulation tends to activate the same muscle groups.

It is therefore important to realise that when electrophysiological observations are used to investigate systematically complex reflex activities, continuous correlation with the clinical features is of paramount importance to the understanding of mechanisms of spasticity.

We thank Professor VA Fasano, Director of the Institute of Neurosurgery, University of Torino, for allowing the investigation to be undertaken and for his guidance and assistance, $\mathrm{Mr}$ A Squazzi for his extensive assistance, and Dr Ken Casey, University of Michigan, for his assistance with the spastic quadriplegia patient.

\section{References}

1 Rushworth G. Spasticity and rigidity: an experimental study and review. J Neurol Neurosurg Psychiatry 1960; 23:99-118.

2 Dietrichson $P$. Phasic ankle reflex in spasticity and Parkinsonian rigidity. The possible role of fusimotor system. Acta Neurol Scand 1973; 47: 22-51.

3 Matthews PBC. The advances of the last decade of animal experimentation upon muscle spindles. In: Desmedt JE, ed. New Advances in EMG and Clinical Neurophysiology, 3. Basel: Karger, 1973: 95-125.

4 Eccles JC. Presynaptic inhibition in the spinal cord. In: Eccles JC, Shade P, eds. Progress in brain research. Amsterdam: Elsevier, 1964; 65-91.

5 Rushworth G, Young RR. The effect of vibration on tonic and phasic reflexes in man. J Physiol 1966; 185:63-4.

6 Burke D. Ashby P. Are spinal "presynaptic" inhibitory mechanisms suppressed in spasticity? J Neurol Sci 1972; 15:321-6.

7 Delwaide PJ. Human monosynaptic reflexes and presynaptic inhibition. In: Desmedt JES, ed. New Development in EMG and Clinical Neurophysiology, 3. Basel: Karger, 1973; 508-22.

8 Veale JL, Rees S, Mark RF. Renshaw cell activity in normal and spastic Man. In: Desmedt J. ed. New Developments in EMG and Clinical Neurophysiology, 3. Basel: Karger, 1973; 523-37.

9 Ashby P, Verrier M, Lightfoot E. Segmental reflex pathways in spinal shock and spinal spasticity in man. J Neurol Neurosurg Psychiatry 1974; 37:1352-60.

10 Ashby P, Verrier M. Neurophysiologic changes in hemiplegia. Neurology [Minneap] 1976; 26: 1145-51.

11 Kanda K, Homma S, Watanabe S. Vibration reflexes in spastic patients. In Desmedt JD, ed. New Developments in EMG and Clinical Neurophysiology, 3. Basel: Karger, 1973; 469-74.

12 Lance JW, Burke D. Andrews CJ. The reflex effect of muscle vibration. Studies on tendon jerk irradiation, phasic reflex inhibition and the tonic vibration reflex. In: Desmedt JE, ed. New Developments in EMG and Clinical Neurophysiology, 3. Basel: Karger, 1973; 444-62.

13 Fasano VA, Barolat-Romana S, Squazzi A. La radicotomie posteriéure fonctionelle dans le traitment de la spasticité' cérébrale. NeuroChirurgie 1976; 22:23-34.

14 Fasano VA, Broggi G, Barolat-Romana G, Squazzi A. The surgical treatment of spasticity in cerebral palsy. Child's Brain 1978; 4:289-305.

15 Fasano VA, Barolat-Romana G, Zeme S, Squazzi A. Electrophysiological assessment of spinal circuits in spasticity by direct dorsal root stimulation. Neurosurg 1979; 4:146-51.

16 Davis R. Spasticity following spinal cord injury. Clin Orthop 1975; 112:66-75.

17 Davis R, Casey K. Bishof's Myelotomy for spastic paraplegia. Congress of Neurological Surgeons 1970.

18 Lloyd DCP. Facilitation and inhibition of spinal motoneurons. J Neurophysiol 1946; 9:421-38. 
19 Decandia M, Provini L, Taborikova H. Mechanisms of the reflex discharge depression in the spinal motoneurone during repetitive orthodromic stimulation. Brain Res 1967; 4:284-91.

20 Renshaw B. Activity in the simplest spinal reflex pathways. J Neurophysiol 1940; 3:373-87.

21 Lloyd DCP. Neuron patterns controlling transmission of ipsilateral hindlimbs reflexes in cat. J Neurophysiol 1943; 6:293-315.

22 Lloyd DCP. Reflex action in relation to the pattern and peripheral source of afferent stimulation. J Neurophysiol 1943; 6:111-9.

23 Magladery JW, Porter WE, Park AM, Teasdall RD. Electrophysiological studies of nerve and reflex activity in normal man. Johns Hopkins Med J 1951; 88:499-510.

24 Murayama S, Smith C. Rigidity of hind limbs of cats produced by occlusion of the spinal cord blood supply. Neurology [Minneap] 1965; 15: 565-77.

25 Barolat-Romana G. Unpublished observations. 1979.

26 Cook WA. Effects of low frequency stimulation of the monosynaptic reflex in man. Neurology 1968; 18:47-51.

27 Jefferson AA, Schlapp W. Some effects of repetitive stimulation of afferents on reflex conduction. In: Malcolm JL, Gray JAB, eds. The spinal cord. Boston: Little Brown \& Co, 1953; 99-117.

28 Lloyd DCP. Reflex depression in rhythmically active monosynaptic reflex pathways. $J$ Gen Physiol 1957; 40:409-25.

29 Ishikawa K, Ott K, Porter R, Stuart D. Low frequency depression of the $H$ wave in normal and spinal man. Exp Neurol 1966; 15:140-56.

30 Curtis DR, Eccles JC. Synaptic action during and after repetitive stimulation. J Physiol 1960; 150:374-98.

31 Gelfan S. Altered spinal motoneurons in dogs with experimental hind limb rigidity. $J$ Neurophysiol 1966; 29:583-611.

32 Matushita A, Smith C. Spinal cord function in postischemic rigidity in the rat. Brain Res 1970; 19:395-410.

33 Van Harreveld A, Spinelli D. Mechanisms of the extensor rigidity caused by spinal cord asphyxiation. In: Bargman W. Shade JP, eds. Progress in Brain Research. Amsterdam: Elsevier, 1964; 174-9.

34 Paillard J. Analyse electrophysiologique et comparison chez l'homme du reflexe de Hoffmann et du reflexe myotatique. Pfluegers Arch 1955; 260:448-79.

35 Magladery JW, Teasdall RD, Park AM, Languth HW. Electrophysiological studies of reflex activity in patients with lesions of the nervous system. I. A comparison of spinal motoneurone excitability following afferent nerve volleys in normal persons and patients with upper motor neurone lesions. Johns Hopkins Med J 1952; 91: 219-44.

36 Taborikova $\mathbf{H}$, Sax DS. Conditioning of $\mathbf{H}$ reflex by a preceding subthreshold $\mathrm{H}$ reflex stimulus. Brain Res 1969; 92:203-12.

37 Masland WS. Facilitation during $\mathbf{H}$ reflex

38 Dimitrijevic MR, Nathan PW. Studies of recovery cycle. Arch Neurol 1972; 26:313-9. spasticity in man 2. Analysis of stretch reflexes in spasticity. Brain 1967; 90:333-58.

39 Eccles JC, Kostyuk P, Schmidt RP. Presynaptic inhibition on the central action of flexor reflex afferents. J Physiol 1962; 161:258-81.

40 Gillies JD, Lance JW, Neilson P, Tassinari CA. Presynaptic inhibition of the monosynaptic reflex by vibration. J Physiol 1969; 205:329-39.

41 Herman R, Mecomber SA. Vibration elicited reflexes in normal and spastic muscles in man. Am J Phys Med 1971; 50:169-83.

42 Ioku M, Nakatani S, Oku I, Jinnai D. The $H$ reflex study with high frequency stimulation. Electromyog 1969; 9:219-27.

43 Teasdal RD, Magladery JW, Ramey EH. Changes in reflex patterns following spinal cord hemisection. Johns Hopkins Med J 1958; 103: 223-35. 